\title{
Small Size Silver Nanoparticle's Corrosive and Hazardous Manifestations on Mature and Developing Kidney Following Accumulation in Pregnant Mice and Offspring's after Serial Oral Bolus Experimental Application: A New Chapter in Teratogenicity and Toxicity Search
}

\section{Pani Jyoti Prakash ${ }^{1 *}$, Singh Royana ${ }^{1}$ and Pani Sankarsan ${ }^{2}$}

${ }^{1}$ Department of Anatomy, Banaras Hindu University Varanasi, UP, 221005, India

${ }^{2}$ Department of Surgery, Nandkumar Y. Tasgaonkar Institute of Medical Science and Research, Karjat, Raigad, Bhivpuri, 410201, India

\begin{abstract}
The most important and worldwide utilized nanomaterial is silver metal nanoparticle which after synthesis changed to colloidal or powdered form. After successful characterization different sizes of these particles measured if intermixed and confirmed to different size ranges. Different sizes segregates into various size groups. Specific small or large size silver in powder form also readily available in market for various applications and experiments after biological or herbal synthesis and characterization. 1 to $20 \mathrm{~nm}$ size ranges are grouped under inconsiderable or smaller size range whereas 20 to $100 \mathrm{~nm}$ size ranges or above sizes are grouped under considerable or bigger size range. Following serial oral ingestion for experiment, aqueous and magnetic stirred synthesized AgNps of less than $20 \mathrm{~nm}$ of null account size accumulate in mature and developing kidneys of pregnant Swiss Albino mice and their freshly born fetuses after passing through blood vessels of pregnant mice and after absorption from gastro intestinal tract and accumulate in mature kidney due to trap inside. These particles also crosses blood placental barrier reaches fetus body in womb and accumulate in developing kidney due to same mechanism. These particles also surprisingly execute sex specific corrosive manifestation. We have examined the corrosive and hazardous effect of 10 gestational days ( 5 to 15 gestational days) serial oral bolus ingestion of 2.75 to $18.5 \mathrm{~nm}$ size range AgNps colloidal solution in a lower dose of 0.35 (1), 0.55 (2) $\mathrm{mg} / \mathrm{kg}$. b.w, in an in between dose of 4 (3), 8 (4) mg/ $\mathrm{kg}$. b.w. and in a higher dose of $12(5)$ and $16(6) \mathrm{mg} / \mathrm{kg}$. b.w. treatment on mature and developing right and left kidneys of pregnant mice and fetuses. Groups were designated as 1(Control); 2, 3, 4, 5 and 6 (Treated). At lower dose we report negligible histological findings and at higher bolus dose we report marked histological findings. This particular size range group silver nano particles (AgNps) treatment turns into insignificant reduction in kidney weight and height at higher dose, with some hemorrhagic focuses along with histological alterations. Predominantly agenesis and severe atrophy of renal corpuscles, increase of urinary space, generalized anasarca of podocytes, degeneration and dysmorphology with congestion of proximal convoluted tubules and distal convoluted tubules, loss of brush border membranes and damage of squamous epithelium of loop of Henley with severe congestion in medullary rays and collecting ducts are observed in routine histology. The in between dose demonstrated in between results. These manifestations are found quite same to chronic and acute renal failure with hematuria. All these alterations, in prolong sustain, could land up to beginning of apoptosis and progress of cell necrosis in these vital organs.
\end{abstract}

Keywords: Nano colloid silver (Ag); Renal system; Kidney toxicity; Cell death, Podocytic cell swelling; Congestion

\section{Introduction}

\section{Small size nanosilver nephrotoxic and dermal ameliorative dilemma}

Small size nanosilver definitely have potential and adverse nephrotoxic dilemma in indirect and direct exposure. Indirect exposure indicates the use of small size nanosilver through dermal route where initially it shows positive response and subsequently negative response. Direct exposure indicates the use of small size nanosilver through oral and other route where most of the time it shows negative response. For aseptic closure dressings of diabetic nephropathy caused complicated diabetic sores, bed sores, carbuncles and traumatic wounds and for preparation of medicated bandages small size of nanosilver ionic metal $\left(\mathrm{Ag}+10^{-9} \mathrm{~nm}\right)$ particles are preferred in an extensive manner [1]. After easy absorption through dermal root these sharp horny small size nano metals produces severe nephrotoxic dilemma after trapping inside the organ because of extensive damage to renal parenchyma. It produces such devastating dilemma while surpassing with urine inside kidney followed by filtration. It reaches kidney after migrating in blood vessels
[2]. Limited in-vitro and in-vivo experiments have proved that small size metallic silver nanoparticle have negative and drastic effects in human and lower animals mature and developing kidney via external surface of the body i.e. dermal route application and absorption, with addition to both way application such as oral bolus exposure and inhalation route exposure certainly evokes increase risk of chronic and acute renal diseases while using drugs having predominant composition of small size metallic nanosilver [3].

*Corresponding author: Prakash JP, Research Scholar, Department of Anatomy Banaras Hindu University Varanasi, UP, 221005, India, Tel: 08433668356; E-mail: Pani/jyotiprakash.pani35@gmail.com

Received July 10, 2017; Accepted August 17, 2017; Published August 25, 2017

Citation: Prakash PJ, Royana S, Sankarsan P (2017) Small Size Silver Nanoparticle's Corrosive and Hazardous Manifestations on Mature and Developing Kidney Following Accumulation in Pregnant Mice and Offspring's after Serial Oral Bolus Experimental Application: A New Chapter in Teratogenicity and Toxicity Search. J Cytol Histol 8: 467. doi: 10.4172/2157-7099.1000467

Copyright: (c) 2017 Prakash PJ, et al. This is an open-access article distributed under the terms of the Creative Commons Attribution License, which permits unrestricted use, distribution, and reproduction in any medium, provided the original author and source are credited. 
Citation: Prakash PJ, Royana S, Sankarsan P (2017) Small Size Silver Nanoparticle's Corrosive and Hazardous Manifestations on Mature and Developing Kidney Following Accumulation in Pregnant Mice and Offspring's after Serial Oral Bolus Experimental Application: A New Chapter in Teratogenicity and Toxicity Search. J Cytol Histol 8: 467. doi: 10.4172/2157-7099.1000467

\section{Size dependant nephrotoxicity focus in indirect response}

Past limited researches exclamated multi thorny pin pointed small size silver nanoparticle have more nephrotoxic nature than bigger ones [4]. Less than 2.75 to $20 \mathrm{~nm}$ range ionic silver nanoparticles ( $\mathrm{Ag}+\mathrm{Nps})$ after serial oral bolus ingestion undergo absorption via various pathways such as gastro intestinal (GI) route, dermal route, respiratory route and other mucosa and sub mucosa [5]. After proper absorption this metallic silver nano meter $\left(10^{-9} \mathrm{~m}\right)$ particles floats and passes through circulatory channels and accumulate in mature liver and kidneys of pregnant mother and then surpassing through umbilical cords and vessels crosses fetoplacental barrier further reaches and accumulate in developing liver and kidneys of fetuses and cause extensive abdominal viscera destruction, which ultimately affects glomerular filtration rate and finally land up to chronic and acute hepatorenal ailments [6]. Apart from these, cellular porous permeability was found indirectly proportional to volume of experimental colloid and time of exposure [7]. Thorny tiny silver nano particle with breadth and diameter below 1.55 to $19.57 \mathrm{~nm}$ range after specific experimental application found to be initiative of certain chronic kidney inflammatory diseases, [8] nano metal of this category also become barrier in proper development of viruses, fungus and certain dangerous parasites. Small size nano particles tremendously heals damaged tissue after hurts from fire injury, traumatic injury and certain diabetic and diseased wound but the negative feedback is after smooth absorption from skin it causes indirect damage to internal organs like liver and kidney followed by chronic deposition [9]. Silver nanoparticles (AgNps) of tiny size range $(2.75$ to $20 \mathrm{~nm}$ ) without delay and smoothly absorbed into body via colloid suspension dermal application in form of ointment, toothpaste, silver foils and drugs [10].

\section{Liberation of ion from metallic nano and spread of virulent toxicity followed by deposition in higher dose}

Some of the past limited study says small size metal silver nanoparticle in colloid or drug form profusely liberates (silver ion) $\mathrm{Ag}+$ metalloid molecules which transferred to circulatory channels from gut and from there followed by chronic deposition evokes toxic responses in vital organs like liver and kidney [11]. Anyway, rapid oral route and subcutaneous application of colloid small (nanosilver ion) Ag+ nano $\left(10^{-9} \mathrm{~m}\right)$ suspension $(1,500$ to $1900 \mathrm{mg} / \mathrm{kg}$ b.w range) in lower group mammals shows life threatening effect in form of vital signs like, death, severe corrosiveness and reactions which causes drastic results for kidney, eye with other associated vision organs and skin [12]. Small size silver nanoparticles because of their thorny surfaces found to be comparatively more toxic to other metal nanoparticles, [13] where pathway of toxicity is still unsolved and unanswered [14].

\section{Objective of the Research}

The aim and objective of this existing research was to evaluate the kidney toxicity risks by application of small size silver nanoparticles (AgNps) morphologically and histologically. And for that we meticulously examined the corrosive effect of lower and higher dose small size nanosilver particles (AgNps) magnetic stirring and cooling colloidal suspension in order to identify morphological and histological alterations in mature and developing kidney of pregnant Swiss Albino mice and their fetuses by serial oral bolus applications for prolong gestational period (10 days i.e. 5 to 15 gestational age), in a positive intension and hope of removing darkness of ignorance by knowledge light beam on this type of concept of corrosive renal cortico medullary influences induced by serial oral bolus of lower and higher dosing, and to assess morphological and histological responses by oral ingestion we preferred specific tuberculin syringe and plain $2 \mathrm{ml}$ and $5 \mathrm{ml}$ disposable syringe and 14 to 15 No. size feeding needle with manually prepared blunt tip feeding method.

\section{Antagonistic effect and fatal consequences after liberation of ions from devices used for surgical intervention}

In contrast of the above views, some old scientific study of recent era quoted that small size nanosilver particles (AgNps) reacts on renal tissue by reduce swelling and executes no dangerous and negative side effects on functions of vital organ like liver, kidney and gonads in lower animal experimental model. So there is lot of potential medical benefits through outer application [15]. But against the previous view-15 some of the past medical and biological journal reported that, many medical and surgical devices like scissor, abdominal clamp, silver threads and silver coated anti cancerous and anti-diabetic drugs liberate silver (Ag) metalloid micro molecules to circulatory system in human body which ultimately deposited in mature and developing liver and kidney and cause its respective toxicity that at the end land up to fatal consequences [11].

\section{Lacunae in stable and reliable data}

The kidney toxicity of small size nanosilver particles (AgNps) has been evaluated in a multiple researches but there is still a lacuna in getting consistent, stable and reliable data. So the present situation needs more research activity for obtaining valid and relevant nephrotoxicity data. In this existing research, our team of scientists made a strong effort to understand renal toxicity in mature and developing stage by studying the serial bolus oral ingestion effect of highly purified, magnetic stirring and cooling prepared and successfully characterized polyvinyl pyrollidone coated small size nanosilver particles (AgNps) on Swiss Albino mice and fetuses kidney's Podocytic, Glomerular cells and other cells with gross morphological deviations in same. The toxicity which executed in different kidney cells of treated small size silver nano colloid is variable and from study point of view is important. Past study proves that small size nanosilver particles (AgNps), when reaches the circulatory channels, floats and afterwards migrated to vital organs and deposited then metabolized in the tissues of reticulo endothelial system and urinary system of the body [11]. Small size nano silver stays in liver and kidney for prolong period once it reaches these vital organs, because of the slow tissue elimination property from these vital organs.

\section{Nephrotoxicity from histological point of view}

In this existing study serial oral bolus small size colloid nanosilver particles (AgNps) toxicity in pregnant Swiss Albino mice and their fetuses, scientists [16] have demonstrated kidney damages in histological view with the help of Nikon, bright field binocular microscope with insignificant histological changes in kidneys in lower dose group and significant histological changes in kidney in higher dose group. Therefore, the Podocytic cell and Glomerular cell with other vital cells of kidney corticomedullary tissue were considered as histological milestone for toxicity. For toxicity evaluations, Podocytic cell and Glomerular cell with other cells its nanosilver viability rate in oral route exposed state hold fully responsible and taken in to account. Because of extensive utilization of small size nanosilver particles (AgNps) in biomedical stream and their effects on human urinary and digestive system, we have designed and prepared this existing manuscript to investigate the possible morphological and histopathological effects in kidney of pregnant mice and fetuses after prolong serial oral bolus exposure during gestational ages from 5 to 15 . 
Citation: Prakash PJ, Royana S, Sankarsan P (2017) Small Size Silver Nanoparticle's Corrosive and Hazardous Manifestations on Mature and Developing Kidney Following Accumulation in Pregnant Mice and Offspring's after Serial Oral Bolus Experimental Application: A New Chapter in Teratogenicity and Toxicity Search. J Cytol Histol 8: 467. doi: 10.4172/2157-7099.1000467

\section{Some of the recent nephrotoxicity research views}

Kermanizadeh et al. propounded that among 10 Engineered Nanomaterials adverse effect to human health highest nephrotoxic effect exhibited by small size silver engineered nano metal. This has been evaluated through a multi laboratory toxicological assessment by a panel of toxicological experts through ENPRA Project. The objective of this assessment is the highlights, limitations, current and future challenges for small size silvernano nephrotoxicity focus $[17,18]$. Jyoti et al. and other scientist quoted that herbal synthesis and characterization of nano silver has ameliorative effect along with nephrotoxic effects [19]. Also some of the recent researches from relevant eminent scientists declares, EPA takes action to protect public from an illegal nano silver pesticide in food containers cites NJ company for selling food containers with an unregistered pesticide warns large retailers not to sell these products. EPA announces registration of nanosilver pesticide product in food container. Because nanosilver pesticides causes severe nephrotoxic dilemma in which consumer led to acute renal shut down and fatal prognostic result appear due to this [20-23]. Gaillet et al. in recent era discovered small size silver nanoparticles their potential negative effects after oral exposure executes severe nephrotoxic effect [24]. Bekele et al. discovered size-dependent antiviral and nephrotoxic effects of small size silver nanoparticles [25]. Verleysen et al. in recent year proved TEM and SP-ICP-MS analysis says release of small size silver nanoparticles cause severe nephrotoxic effect in drug manufacturing process but also utilized significantly for decoration of pastry [26]. Williams et al. reported effects of sub chronic exposure of silver nanoparticles on micro biota and lower animal cause severe nephrotoxicity [27]. Bastos et al. propounded that the influence of Citrate or PEG coating on silver nanoparticle arouses toxicity to a human keratinocyte and kidney cell line [28]. Boudreau et al. recently discovered differential effects of small size silver nanoparticles and silver ions on tissue accumulation, distribution, and nephrotoxicity in the lower animal following daily, oral gavage administration for 13-Weeks in repeated mode [29]. Georgantzopoulou et al. and their team recently researched and found effects of silver nanoparticles and ions on a co-culture model for the gastrointestinal epithelium. They also found toxic sequence in kidney cell line in this experiment [30]. Gordon et al. recently researched non-animal models of epithelial barriers (skin, kidney, intestine and lung) in research, industrial applications and found regulatory toxicology dilemma in these vital organs in histological and gross view [31].

\section{Materials and Methods}

\section{Central animal ethical committee approval}

The animal experiments were carried out after the study was approved by central institution, by central animal ethical committee Institute of Medical Sciences (IMS), Banaras Hindu University (BHU) Varanasi, Uttarpradesh, India, 221005 (No. Dean/2014/CAEC/614Dated-30.05.2014) (Concern letter attached at the end of the manuscript after references)

\section{Primate vertebrate with lower group of animal for experiment}

9 to 12 weeks old Pregnant Swiss Albino mice from randomly breed colonies (25.5-35.7 gm) from central animal house Institute of Medical Sciences Banaras Hindu University were chosen and experiment conducted in Department of Anatomy IMS, BHU. Total animals were getting pregnant by mature male of same variety, dissected and under most aseptic condition mature and developing kidneys are collected in clean Petridis on same standardized histology laboratory and animal house attached animal dissection hall. They were kept in an animal room for copulation where the temperature $\left(20 \pm 4^{\circ} \mathrm{C}\right)$, humidity $(45-$ $55 \%)$, and day: night cycle (12:12 light: dark) were maintained.

\section{Synthesis of small size colloid silver nanoparticles}

$30 \mathrm{ml}$ of $0.002 \mathrm{M}$ fresh sodium borohydride $\left(\mathrm{NaBH}_{4}\right)$ solution is added to an Erlenmeyer flask. A magnetic stir bar is dipped to it and the flask is placed in an ice berg bath surrounding to it on a stir plate machine settled 400 rotation per minute (RPM). The liquid is stirred and cooled for 15 to $20 \mathrm{~min}$. $2 \mathrm{ml}$ of $0.001 \mathrm{M}$ freshly prepared silver nitrate $\left(\mathrm{AgNO}_{3}\right)$ solution dripped into the previous solution and stirring is continued at the same time with magnetic wave throw. Dripping is done approximately a drop per second. Stirring is stopped as soon as all of the silver nitrate $\mathrm{AgNO}_{3}$ is added. The formation of silver nanoparticles can be observed by a change of the solution to yellow color. $1.5 \mathrm{M}$ sodium chloride $\left(\mathrm{NaCl}_{2}\right)$ solution few drops adding to suspension converts darker yellow, then grey as the nanoparticles aggregate. Addition of few drops of $0.3 \%$ polyvinyl pyrollidone (PVP) prevents aggregation [32].

\section{Selection of mature and developing kidney for histology based on size dose group and dissection}

The corrosive and hazardous effect of small size colloidal silver nano was examined by giving 10 days ( 5 to 15 gestational days) serial oral bolus ingestion. In Control group (group 1), pregnant mice used for experiment was $(n=10)$. Same number of pregnant mice was used for other treated groups ( 2 to 6 treated groups) in this experiment $(\mathrm{n}=10)$. Mother and Freshly delivered fetuses were freshly dissected by caesarian section method for collection of mature and developing right and left kidney and preserved in $10 \%$ formalin for fixation group wise. Bodies were buried in unused soil after collection of organ. After proper fixation organs were processed by routine histological method like hematoxylin and eosin staining method ( $\mathrm{H}$ and $\mathrm{E}$ ) for light, bright and dark microscopic view. At the end histological photographs were taken by Nikon binocular microscope for comparison between control group and treated groups.

\section{Analysis of statistics by Prism 5 and SPSS statistical software}

The comparative results were expressed as mean (mean \pm standard deviation (S.D)) from post hoc analysis. Data were analyzed statistically using one-way analysis of variance (ANOVA) followed by t test, $\mathrm{f}$ test and Dunnett test. A predictive value of $(\mathrm{P}<0.005)$ was considered statistically highly significant.

\section{Result}

\section{Gross anatomical deviation in treated mothers}

At light bolus we report negligible gross findings and at heavy bolus we report marked gross findings. This particular size group AgNps treatment turns into reduction in kidney weight and height, some hemorrhagic consequences (Figure 1).

On gross examination of pregnant mother kidney marked reduction in the size observed in 4, 8, 12 and $16 \mathrm{mg} / \mathrm{kg}$ b.w. 2.75 to 18.5 $\mathrm{nm}$ mean size range nanosilver particles colloid (AgNps) treated group when compared with the control. The kidney also showed significant reduction in the size $(\mathrm{P}<0.005)$ with marked haemorrhage in 12 and $16 \mathrm{mg} / \mathrm{kg} / \mathrm{b} . w .2 .75$ to $18.5 \mathrm{~nm}$ mean size range nanosilver particles (AgNps) treated group, when compared with control group, though marked haemorrhage observed in other treated groups but it was not 
Citation: Prakash PJ, Royana S, Sankarsan P (2017) Small Size Silver Nanoparticle's Corrosive and Hazardous Manifestations on Mature and Developing Kidney Following Accumulation in Pregnant Mice and Offspring's after Serial Oral Bolus Experimental Application: A New Chapter in Teratogenicity and Toxicity Search. J Cytol Histol 8: 467. doi: 10.4172/2157-7099.1000467

significant $(\mathrm{P}>0.005) .4$ and $8 \mathrm{mg} / \mathrm{kg}$ b.w. treated group showed in between results (Table 1).

Mean of kidney weights, mean body weight and kidney weight to body weight ratio (Table 2 and Figure 2).

\section{Gross anatomical deviation in treated fetuses}

On gross examination of fetus kidney marked reduction in the size was observed in 12 and $16 \mathrm{mg} / \mathrm{kg}$ b.w .2 .75 tol8.5 nanometer size range nanosilver particles (AgNps) treated group when compared with control group foetus kidney, $(\mathrm{P}<0.005)$ though reduction of size was observed in other treated groups $(0.35,0.55,4$ and $8 \mathrm{mg} / \mathrm{kg}$ b.w.) but it

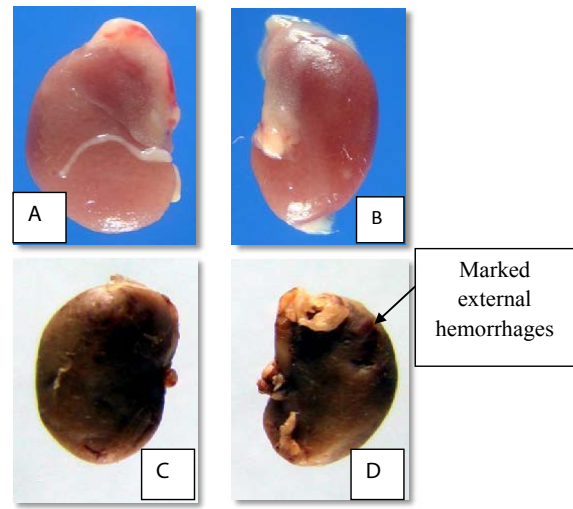

Figure 1: (A-D) Pregnant mother dissected kidney from Sham control $A$ and B. 12 and $16 \mathrm{mg} / \mathrm{kg} / \mathrm{b} . \mathrm{w}$ small size nanosilver particles (AgNps) treated group C and D.

\begin{tabular}{|c|c|c|}
\hline Groups & $\begin{array}{c}\text { Pregnant mice kidney } \\
\text { Length in cm }\end{array}$ & Pregnant mice kidney Breadth in cm \\
\hline Control & $1.32 \pm 0.006$ & $0.75 \pm 0.004$ \\
\hline $0.35 \mathrm{mg}$. & $1.29 \pm 0.006$ & $0.74 \pm 0.004$ \\
\hline $0.55 \mathrm{mg}$ & $1.28 \pm 0.006$ & $0.73 \pm 0.003$ \\
\hline $4 \mathrm{mg}$ & $1.26 \pm 0.005$ & $0.71 \pm 0.003$ \\
\hline $8 \mathrm{mg}$ & $1.25 \pm 0.005$ & $0.69 \pm 0.003$ \\
\hline $12 \mathrm{mg}$ & $1.13 \pm 0.004$ & $0.57 \pm 0.003$ \\
\hline $16 \mathrm{mg}$. & $1.22 \pm 0.002$ & $0.66 \pm 0.003$ \\
\hline
\end{tabular}

Anova-p>1.1 (Insignificant); Manova test-:Hypothesis dF-6, Error dF-1, Insig Pillai trace-1, Wilks lambda-1.12, Hottelling trace-12544.419, Roy's largest root12544.419, 1.12 (Insignificant), F-1757.403 (Insignificant control vs. 0.3, 0.55, 4 $8 \mathrm{mg}$ and Insignificant control vs. 12 and $16 \mathrm{mg}$ tr.gr. $)=p<0.005$; $(p>0.005$ for 0.3 , $0.55,4,8 \mathrm{mg}$ tr.gr.).

Table 1: Different anthropometrical measures of kidney from control and treated group pregnant mother parameters taken length and breadth in $\mathrm{cm}$ (kidney) was not significant $(\mathrm{P}>0.005)$. Specifically 4 and $8 \mathrm{mg} / \mathrm{kg}$ b.w. treated group showed in between results (Figure 3 and Table 3 ).

\section{Histological Alteration}

At light bolus negligible histological findings were reported but in heavy bolus marked histological findings were reported. Predominantly agenesis and severe atrophy of renal corpuscles, increase of urinary space, generalized anasarca of podocytes, degeneration and dysmorphology with congestion of proximal convoluted tubules (PCT) and distal convoluted tubules (DCT), loss of brush border membranes and damage of squamous epithelium of loop of Henley with severe congestion in medullary rays and collecting ducts are observed in routine histology. These manifestations are found quite same to chronic and acute renal failure with hematuria. Final conclusive stanza of our study explains why and how prolongs period small size colloid AgNps oral ingestion could initiate histomorphological destruction to mature and developing kidney causing erosion and damage.

\section{Histological alterations in treated mothers}

In histology deviation $0.35,0.55,4,8,12$ and $16 \mathrm{mg} / \mathrm{kg}$ b.w. 2.75 to 18.5 size range AgNps treated pregnant mother kidney showed certain changes. Marked degenerative changes observed in higher doses group as compared to the control group (Figure $4 \mathrm{~A}$ and $4 \mathrm{~B}$ ). The $0.35 \mathrm{mg} /$ $\mathrm{kg}$ b.w. 2.75 to 18.5 size range particle colloidal silver treated pregnant mother kidney showed no changes when compared to that of the normal control (Figure 4C and 4D) also at higher magnification (400 times $(40 \mathrm{x})$ ) showed almost no changes The $0.55 \mathrm{mg} / \mathrm{kg}$ b.w. 2.75 to 18.5 size range particle colloidal silver treated pregnant mother kidney showed almost same feature as that of the normal (Figure $4 \mathrm{E}$ and $4 \mathrm{~F}$ ). The $4 \mathrm{mg} / \mathrm{kg}$ b.w. 2.75 to 18.5 size range particle colloidal silver treated pregnant mother kidney showed moderate percentage atrophy of Malpighian corpuscles, complete absence of renal corpuscles, mild to moderate proximal and distal convoluted tubule degeneration at 100 times magnification (10x) (Figure 4G) also at higher magnification (400 times $(40 \mathrm{x}))$ the pregnant mother kidney showed increase of urinary space (Figure $4 \mathrm{H}$ ). The $8 \mathrm{mg} / \mathrm{kg}$ b.w. 2.75 to 18.5 size range particle colloidal silver treated pregnant mother kidney showed moderate interstitial hemorrhages, necrosis of renal corpuscles, congestion and degeneration of proximal and distal convoluted tubules, degeneration of medullary rays and collecting ducts at 100 times magnification (10x) (Figure $4 \mathrm{I})$ at higher magnification $(400$ times $(40 \mathrm{x})$ ) the pregnant mother kidney showed increased urinary space, proximal and distal convoluted tubules degeneration, atrophy of renal corpuscles which found to be higher in comparison to $4 \mathrm{mg} / \mathrm{kg}$ b.w. group (Figure $4 \mathrm{~J}$ ). The $12 \mathrm{mg} / \mathrm{kg}$ b.w. 2.75 to 18.5 size range particle colloidal silver treated pregnant mother kidney showed multiple interstitial hemorrhagic

\begin{tabular}{|c|c|c|c|c|c|c|c|c|}
\hline Group & Number (N) & Kidney weight (g) & $\begin{array}{l}\text { Body weight (g) } \\
\text { G.D.0 to G.D.18 }\end{array}$ & $\begin{array}{l}\text { Kidney to Body wt. ratio } \\
\text { (Mean } \pm \text { S.D) }\end{array}$ & F value & df1, df2 & $P$ value & $\begin{array}{l}\text { Dunnett2-sided } \\
\text { test (Sig.) }\end{array}$ \\
\hline Control (*1) & 15 & $1.813 \pm 0.09$ & $38.34 \mathrm{E} \pm 5.24$ & $0.188 \pm 0.038$ & 82.457 & & & \\
\hline $0.35 \mathrm{mg}\left({ }^{*} 2\right)$ & 8 & $1.795 \pm 0.08$ & $38.26 \mathrm{E} \pm 5.17$ & $0.1874 \pm 0.034$ & & 2,27 & 0.003 & $p<0.005$ \\
\hline $0.55 \mathrm{mg}\left({ }^{*} 3\right)$ & 7 & $1.776 \pm 0.08$ & $38.19 E \pm 5.10$ & $0.1858 \pm 0.043$ & & & & \\
\hline 4 mg (*4) & 8 & $1.625 \pm 0.0135$ & $37.61 \mathrm{E} \pm 4.23$ & $0.1728 \pm 0.006$ & & & & \\
\hline $8 \mathrm{mg}\left({ }^{*} 5\right)$ & 7 & $1.4205 \pm 0.0305$ & $37.38 \mathrm{E} \pm 3.81$ & $0.1522 \pm 0.016$ & & & & \\
\hline 12 mg $\left({ }^{*} 6\right)$ & 8 & $1.232 \pm 0.0375$ & $37.15 E \pm 3.39$ & $0.1326 \pm 0.022$ & & & & \\
\hline $16 \mathrm{mg}\left({ }^{\star} 7\right)$ & 7 & $1.0435 \pm 0.0375$ & $36.92 E \pm 2.97$ & $0.1130 \pm 0.025$ & & & & \\
\hline
\end{tabular}

*1=Control group, "2=0.35 mg AgNps tr.gr., "3=0.55 mg AgNps tr.gr., *4=4 mg AgNps tr.gr., " $5=8$ mg AgNps tr.gr., "6=12 mg AgNps Tr .Gr., "7=16 mg AgNps Tr .Gr./1 vs. 2, 3 , 4, 5>0.005 (Control group insignificantly compared with lower dose and in between dose treated groups); 1 vs. $6,7<0.005$ (Control group significantly compared with higher dose treated groups $) \times($ Charles Dunnet is a statistical applicative soft wire which compares control with treated groups in this comparison probability value is presented as "p" either $>$ (insignificant relation) or $<$ (significant relation) than value 0.005 ).

Table 2: Mean \pm S.D of pregnant mother kidney weight, body weight and kidney to body weight ratio. 
Citation: Prakash PJ, Royana S, Sankarsan P (2017) Small Size Silver Nanoparticle's Corrosive and Hazardous Manifestations on Mature and Developing Kidney Following Accumulation in Pregnant Mice and Offspring's after Serial Oral Bolus Experimental Application: A New Chapter in Teratogenicity and Toxicity Search. J Cytol Histol 8: 467. doi: 10.4172/2157-7099.1000467

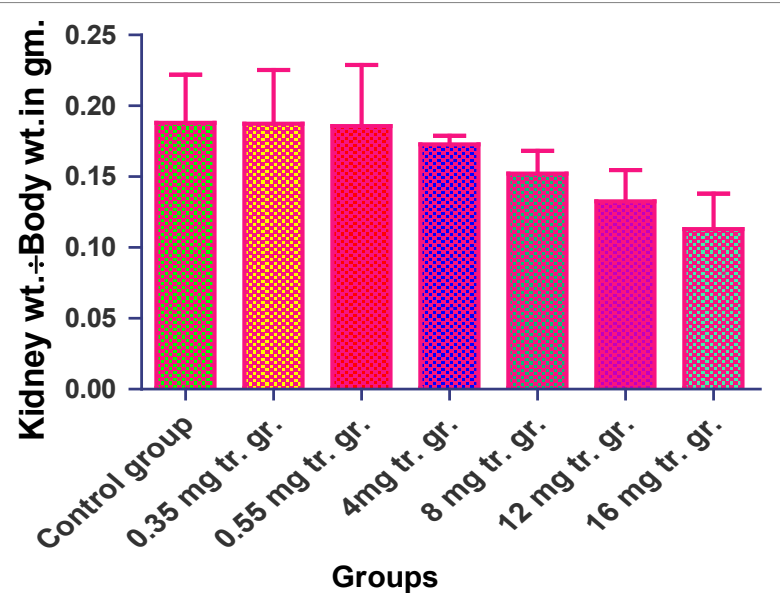

Figure 2: Mean \pm S.D. of kidney wt/body wt. of all pregnant mothers from control and treated groups. The mean \pm S.D. of all pregnant mothers kidney weight/body weight level was found $0.188 \pm 0.038$ in group1 (Sham control group), $0.1874 \pm 0.034$ in group 2 ( $0.35 \mathrm{mg} / \mathrm{kg} \mathrm{b.w.} \mathrm{AgNps} \mathrm{tr.gr.),} 0.1858 \pm 0.043$ in group3 (0.55 mg/kg b.w. AgNps tr.gr.), $0.1728 \pm 0.006$ in group $4(4 \mathrm{mg} / \mathrm{kg}$ b.w. AgNps tr.gr.), $0.1522 \pm 0.016$ in group5 ( $8 \mathrm{mg} / \mathrm{kg}$ b.w. AgNps tr.gr.), 0.1326 \pm 0.022 in group $6(12 \mathrm{mg} / \mathrm{kg} \mathrm{b} . \mathrm{w}$. AgNps tr.gr.) $0.1130 \pm 0.025$ in group7 (16 mg/ kg b.w. AgNps tr.gr.) (Table 2) The group 2, 3, 4, 5, shows insignificant relation verses group $1(p>0.005)$ and group 6 and 7 shows significant relation verses group $1(\mathrm{p}<0.005)$ group1 showed statistically highly significant (Dunnett value $\mathrm{P}<0.005$ verses group 6 and 7 ). But on comparison of kidney weight to body weight ratio level between different groups, the progressive decrease in the value of group $2,3,4,5,6$ and 7 was found highly significant relations $(p<0.005)$ $(\mathrm{F}=82.457)$ in comparison to group 1 (Table 2).

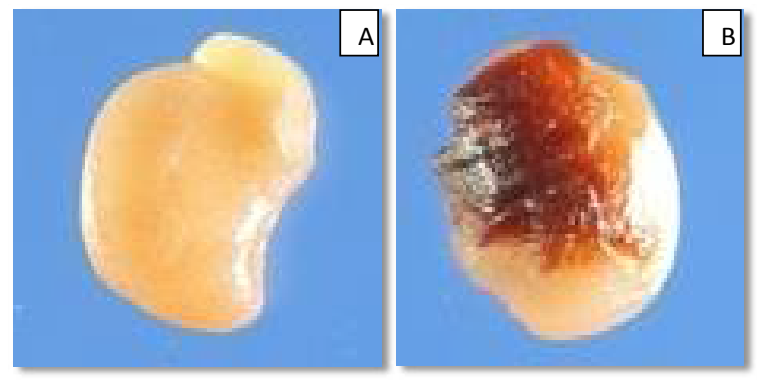

Figure 3: A. Control fetus kidney B: $12 \mathrm{mg}$ tr.gr. fetus kidney with marked hemorrhage.

\begin{tabular}{|c|c|c|}
\hline Groups & $\begin{array}{c}\text { Fetus kidney } \\
\text { Length in cm }\end{array}$ & $\begin{array}{c}\text { Fetus kidney } \\
\text { Breadth in cm }\end{array}$ \\
\hline Control & $0.3 \pm 0.002$ & $0.25 \pm 0.002$ \\
\hline 0.35 mg tr.gr. & $0.29 \pm 0.002$ & $0.24 \pm 0.002$ \\
\hline 0.55 mg tr.gr. & $0.28 \pm 0.002$ & $0.23 \pm 0.002$ \\
\hline 4 mg tr.gr. & $0.26 \pm 0.002$ & $0.22 \pm 0.001$ \\
\hline 8 mg tr.gr. & $0.25 \pm 0.002$ & $0.21 \pm 0.001$ \\
\hline 12 mg tr.gr. & $0.18 \pm 0.001$ & $0.15 \pm 0.001$ \\
\hline 16 mg tr.gr. & $0.24 \pm 0.002$ & $0.21 \pm 0.001$ \\
\hline
\end{tabular}

Anova-p>0.992 (Insignificant); Manova test: Hypothesis dF-2, Error dF-0.5, Insig. Pillai trace-0.33, Wilks lambda- 0.42 , Hottelling trace-7565.300, Roy's largest root2565.300,1.02 (Insignificant), F-127.13 (Insignificant control vs. 0.3, 0.55, 4, $8 \mathrm{mg}$ and Insignificant control vs. 12 and $16 \mathrm{mg}$ tr.gr. $)=p<0.005 ;(p>0.005$ for $0.3,0.55$, 4 , $8 \mathrm{mg}$ tr.gr.) Mean \pm S.D. of of length and breadth of fetus kidney from control to treated group given in Table 3 (Marked reduction in lengths are Italicized).

Table 3: Reduction in the foetus kidney size in 2.75 to $18.5 \mathrm{~nm}$ size range silver Nano particle treated group. patches, maximum number and severe Malpighian corpuscular atrophy, severe degeneration of proximal and distal convoluted tubules at 100 times magnification (10x) (Figure $4 \mathrm{~K}$ ) at higher magnification (400 times $(40 \mathrm{x}))$ the pregnant mother kidney showed increased urinary space, severe degenerations of lining cells of proximal and distal convoluted tubules which is found higher in comparison to $8 \mathrm{mg} /$ $\mathrm{kg}$ b.w. treated group (Figure $4 \mathrm{~L}$ ). The $16 \mathrm{mg} / \mathrm{kg}$ b.w. 2.75 to 18.5 size range particle colloidal silver treated pregnant mother kidney showed highest percentage of renal corpuscular atrophy, absence of renal corpuscles, severe degenerations of proximal and distal convoluted tubules and their lining cells either absence of alignment disturbance at 100 times magnification (10x) (Figure 4M) at higher magnification (400 times (40x)) the pregnant mother kidney showed highest intensity of increase of urinary space, severe congestion of proximal and distal convoluted tubules which is found higher intensity in comparison to12 $\mathrm{mg} / \mathrm{kg}$ b.w. group (Figure $4 \mathrm{~N}$ ).

\section{Histological alterations in treated fetuses}

In histology deviation $0.35,0.55,4,8,12$ and $16 \mathrm{mg} / \mathrm{kg}$ b.w. 2.75 to 18.5 size range AgNps treated fetuses kidney showed certain changes. Marked degenerative changes observed in higher doses group as compared to the control group (Figure $5 \mathrm{~A}$ ). The $0.35 \mathrm{mg} / \mathrm{kg}$ b.w. 2.75 to $18.5 \mathrm{~nm}$ size range particle colloidal silver treated fetuses kidney showed no changes when compared to that of the normal control (Figure 5B) also no changes seen at at higher magnification (400 times (40x)). The $0.55 \mathrm{mg} / \mathrm{kg}$ b.w. 2.75 to $18.5 \mathrm{~nm}$ size range particle colloidal silver treated fetuses' kidney showed the same, same feature as that of the normal (Figure 5C). The $4 \mathrm{mg} / \mathrm{kg}$ b.w. 2.75 to $18.5 \mathrm{~nm}$ size range particle colloidal silver treated fetus kidney showed moderate congestion of inner lumen of proximal convoluted tubule and distal convoluted tubule, moderate degeneration with break of the wall of proximal and distal convoluted tubule it's dysmorpholgy, degeneration of lining Podocytic and Glomerular cells of proximal convoluted tubules at 400 times magnification (40x) (Figure 5D). The $8 \mathrm{mg} / \mathrm{kg}$ b.w. 2.75 to $18.5 \mathrm{~nm}$ size range particle colloidal silver treated fetus kidney showed multiple discrete hemorrhagic patches, moderate to severe congestion of inner lumen of proximal and distal convoluted tubules, break in the wall of proximal convoluted tubules, degeneration , moderate to severe atrophy or even absence of renal corpuscles and increase of urinary space, lymphocyte infiltration at 400 times (40x) magnification (Figure 5E) same thing is observed in $12 \mathrm{mg}$ and $16 \mathrm{mg}$ smaller particle treated group fetuses but the intensity of such feature increased (extreme severe) in comparison to 4 and $8 \mathrm{mg} / \mathrm{kg} /$ day $20 \mathrm{~nm}$ mean sized particle treated group (Figure 5F and 5G).

\section{Findings}

Group 2 treated fetus kidney group showed moderate congestion of proximal and distal convoluted tubule and degeneration of their lining cell, Group 3 treated fetus kidney showed more or less same features but the intensity increases, Group 4 treated group fetus kidney severe congestion of proximal convoluted tubules (PCT) and distal convoluted tubules (DCT), complete degeneration of their lining cells, severe atrophy of renal corpuscles and even absence, Group 5 treated group fetus kidney showed severe atrophy of renal corpuscles even absence, severe reduction of lining cells of proximal convoluted tubules (PCT) and distal convoluted tubules (DCT), Group 6 treated group fetus kidney showed interstitial hemorrhagic focus, complete degeneration of renal corpuscles, severe congestion and dysmorphology of proximal convoluted tubules (PCT) and distal convoluted tubules DCT lymphocytic infiltration, Group 7 treated group fetus kidney 
Citation: Prakash PJ, Royana S, Sankarsan P (2017) Small Size Silver Nanoparticle's Corrosive and Hazardous Manifestations on Mature and Developing Kidney Following Accumulation in Pregnant Mice and Offspring's after Serial Oral Bolus Experimental Application: A New Chapter in Teratogenicity and Toxicity Search. J Cytol Histol 8: 467. doi: 10.4172/2157-7099.1000467
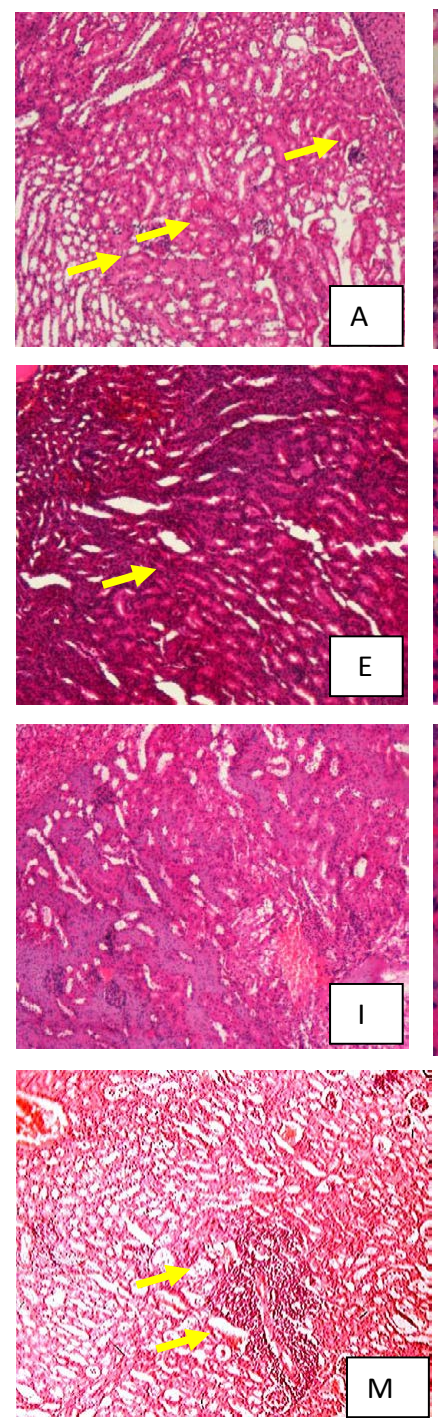
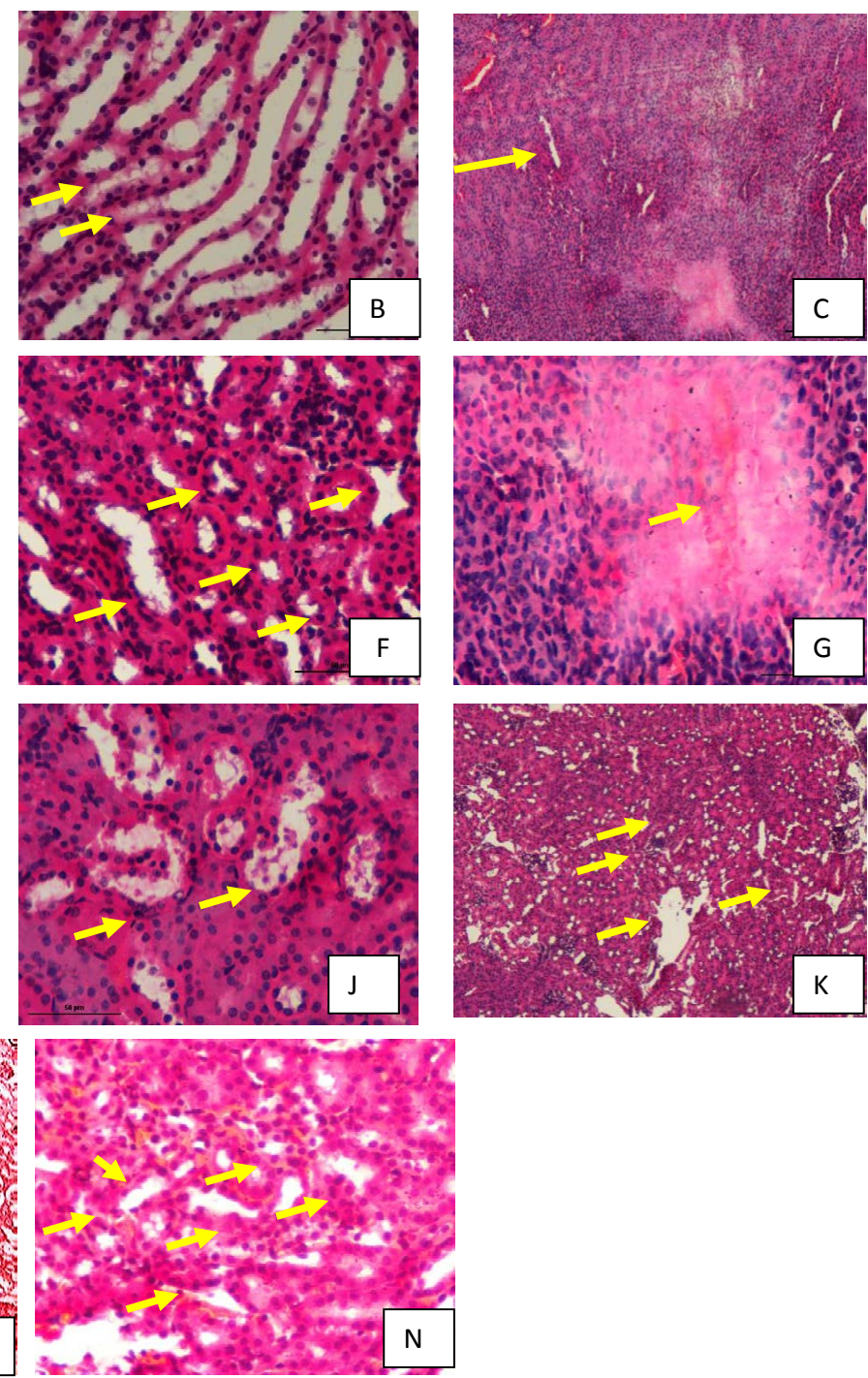

Figure 4: Photomicrograph of the pregnant mother kidney from group 1. (A and B) Control pregnant mother liver (10x and 40x respectively). Photomicrograph of the pregnant mother kidney from group 2. (C and D) Group 2 treated pregnant mother kidney (10x and 40x respectively). Photomicrograph of the pregnant mother kidney from group 3. (E and F) Group 3 treated pregnant mother kidney (10x and 40x respectively). Photomicrograph of the pregnant mother kidney from group 4. (G and $\mathbf{H}$ ) Group 4 treated pregnant mother kidney (10x and 40x respectively). Photomicrograph of the pregnant mother kidney from group 6. (K and L) Group 6 treated pregnant mother kidney (10x and 40x respectively). (I and J) Photomicrograph of the pregnant mother kidney from group 7. (M and N) Group 7 treated pregnant mother kidney (10x and 40x respectively). The lower dose treated group showed similar architecture as that of the control normal kidney. Findings - Minimal congestion of proximal convoluted tubules (PCT) distal convoluted tubules (DCT) (yellow arrow), degeneration of lining cell (yellow arrow). In between dose group showed in between result. Higher treated group showed different architecture from the control normal kidney. Findings - Interstitial hemorrhage and degeneration and damage proximal convoluted tubules (PCT) and dismal convoluted tubules (DCT) (yellow arrow), Glomerular atrophy, degeneration of lining cell of proximal convoluted tubules (PCT), distal convoluted tubules (DCT) and collecting duct, increase urinary space, Glomerular necrosis and agenesis (yellow arrow).

showed same thing but the intensity found increases (all white arrow).

\section{Discussion}

Kidney status is reflected more by creatinine rather than urea. Small size (2.75 to $18.5 \mathrm{~nm}$ size range) Silver nanoparticles (AgNps) affects alteration in kidney status (excessive creatinine and urea) in mice like lower animals but in human still it is not proved. The preliminary essential amino acid breaks down to protein after digestion of food and the protein finally breaks down to urea and creatinine (skeletal muscle waste) which remains as principal waste constituent of urine and eliminates regularly in urination after passing through circulatory channels. In Uremia when urea and creatinine is found in peak in blood it proves that kidney land up in fail status or the person is undergoing dehydration having suddenly suffering from low percentage of water $\left(\mathrm{H}_{2} \mathrm{O}\right)$ in body. Till today the conclusion is not achieved whether the nephrotoxicity of small size Silver nanoparticles (AgNps) is for liberation of ionic silver (Ag+ ion) or particularly this category silvernano show nephrotoxic effect [33-35]. Inconsiderable breadth and length particle silvernano were known for smooth and easy possible penetration into tissue and cell of living organisms, and its accumulation in those with possibilities of severe nephrotoxic effects. Various past studies have reported the uptake of very small size Silver nanoparticles (AgNps) in various group cells and their cell lines [36-39]. Inside body silver biospread researches enlighten the fact that 
Citation: Prakash PJ, Royana S, Sankarsan P (2017) Small Size Silver Nanoparticle's Corrosive and Hazardous Manifestations on Mature and Developing Kidney Following Accumulation in Pregnant Mice and Offspring's after Serial Oral Bolus Experimental Application: A New Chapter in Teratogenicity and Toxicity Search. J Cytol Histol 8: 467. doi: 10.4172/2157-7099.1000467
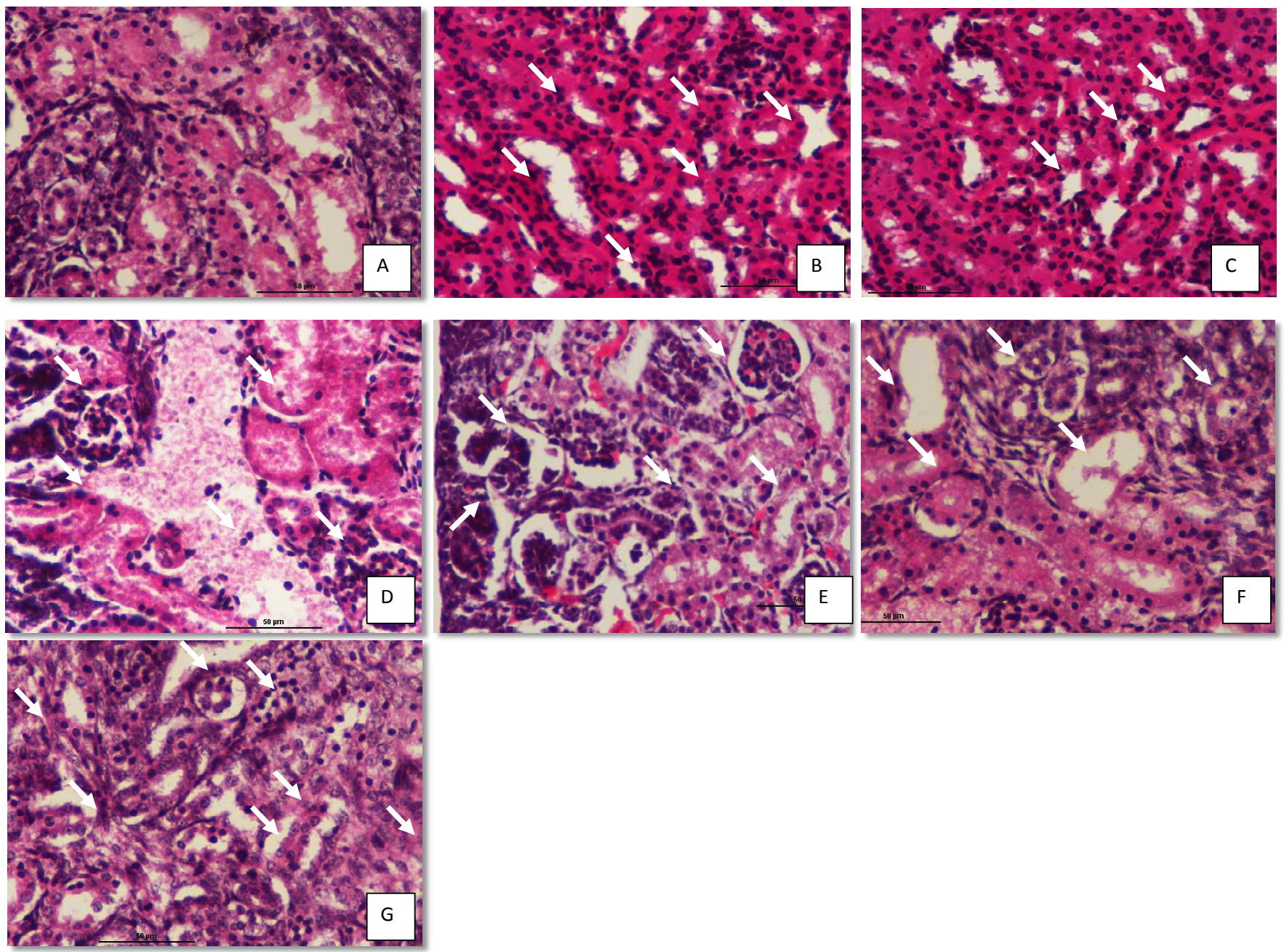

Figure 5: A. Photomicrograph of the fetus kidney from group 1A. Group 1 fetus mother kidney (40x). B. Photomicrograph of the fetus kidney from group 2A. Group 2 fetus mother kidneys (40x). C. Photomicrograph of the fetus kidney from group 3A. Group 3 fetus mother kidney (40x). D. Photomicrograph of the fetus kidney from group 4. (A) Group 4 fetus mother kidney (40x). E. Photomicrograph of the fetus kidney from group 5. (A) Group 5 fetus mother kidney (40x). F: Photomicrograph of the fetus kidney from group 6. (A) Group 6 fetus mother kidney (40x). G. Photomicrograph of the fetus kidney from group 7 . (A) Group 7 fetus mother kidney (40x). The control group showed similar architecture as that of the control normal kidney.

the main target organs for nano silver deposition are kidneys but brain, liver, spleen and heart shares some percentages of deposition [40]. Scientists of present era through research [41] demonstrated that with highest 28 days exposure by intra muscular injectable route the amount and concentration of silver in the kidneys increases in lower animals. The same scientist also discovered when silver is passing through urine in very negotiable amount during urination it indicates same small size Silver nanoparticles (AgNps) accumulate in the kidneys [41]. Therefore, we selected all kidney cells for histological view and corticomedullary kidney tissue for this type of small size silvernano (AgNps) oral bolus ingestion nephrotoxicity. Through gross and histological experiment in normal and treated lower animal (mice) kidney we demonstrated toxic sequence as a devastated effect of small size nanosilver. We histologically examined the chronic deposition of both small size Silver nanoparticles and silver ion $(\mathrm{Ag}+)$ in all kidney cells at different doses. Past history says endocytosis is the mechanism by which silver nanoparticles are engulfed by cells, whereas transport proteins are responsible for the efficient pass of metallic ions which is helped by transport protein through the cell membrane gap junction and cause toxicity [42]. Small size nanoparticles easily migrate through nuclear and cellular pore complexes for intra nuclear toxicity in treated kidney cells [43]. Easy intra cellular pathway migration biokinetics of AgNps, intracellular spread and exocytose ability significantly help to invade toxicity. As per the past research ionic and colloidal form of small silvernano had a greater nephrotoxic effect $[44,45]$. Silver+ ion liberates from nanosilver particles (AgNps) in very low grade percentage, so the grade of small size nano silver nephrotoxic effect dependable on nano scale dimension.

In this existing research, we identified and evaluated the corrosive and hazardous effects of small size silver nanoparticle (2.75 to 18.5 $\mathrm{nm}$ size ranges) on mature and developing kidneys using pregnant Swiss Albino mice and their fetuses treated with serial oral bolus administration of colloid nanosilver (AgNps) at different doses. 0.35, $0.55 \mathrm{mg} / \mathrm{kg}$ b.w (smaller dose); $4,8 \mathrm{mg} / \mathrm{kg}$ b.w (in between dose) and 12 and $16 \mathrm{mg} / \mathrm{kg}$ b.w (higher dose). We found both gross and histological hazards. At smaller dose treated mothers demonstrated negligible gross anatomical deviation, at smaller dose oral ingestion negligible gross 
Citation: Prakash PJ, Royana S, Sankarsan P (2017) Small Size Silver Nanoparticle's Corrosive and Hazardous Manifestations on Mature and Developing Kidney Following Accumulation in Pregnant Mice and Offspring's after Serial Oral Bolus Experimental Application: A New Chapter in Teratogenicity and Toxicity Search. J Cytol Histol 8: 467. doi: 10.4172/2157-7099.1000467

findings are evidenced and at higher dose marked gross findings are evidenced in between dose evidenced in between results. This particular size group nanosilver particles (AgNps) treatment turns into reduction in kidney weight and height, some hemorrhagic consequences. On gross examination of pregnant mother kidney marked reduction in the size observed in 4, 5, 6 and 7 treated group when compared with the control. The kidney also showed significant reduction in the size with marked haemorrhage in 6 and 7 treated group, when compared with control group, though marked haemorrhage observed in other treated groups but it was not significant. 4 and 5 group showed in between results (Table 1). The group 2, 3, 4, 5, shows insignificant relation verses group 1 and group 6 and 7 shows significant relation verses group 1 showed statistically highly significant. Specifically group 4 and 5 showed in between result. But On comparison of kidney weight to body weight ratio level between different groups, the progressive decrease in the value of group 2, 3, 4, 5, 6 and 7 was found highly significant relations in comparison to group 1 (Table 2).

Gross anatomical deviation of small size colloid silver nano treated fetuses exhibited marked reduction in the size of fetus kidney which was significantly evidenced in 12 and $16 \mathrm{mg} / \mathrm{kg}$ b.w treated.group when compared with control group foetus kidney, though reduction of size was observed in other treated groups $(0.35,0.55,4$ and $8 \mathrm{mg} / \mathrm{kg}$ b.w. but it was not significant (Table 3) Group 4 and 5 showed in between results.

In histology deviation $0.35,0.55,4,8,12$ and $16 \mathrm{mg} / \mathrm{kg}$ b.w. 2.75 to 18.5 size range $\mathrm{AgNps}$ treated pregnant mother kidney showed certain changes. Marked degenerative changes observed in higher doses group (6 and 7) as compared to the control group (Figure 4A and 4B). The group 2 treated pregnant mother kidney showed no changes when compared to that of the normal control group 1 (Figure 4C and 4D) at higher magnification (400 times (40x)). The group 3 treated pregnant mother kidney showed almost same feature as that of the normal (Figure $4 \mathrm{E}$ and $4 \mathrm{~F}$ ). The group 4 treated pregnant mother kidney showed moderate percentage atrophy of Malpighian corpuscles, complete absence of renal corpuscles, mild to moderate proximal and distal convoluted tubule degeneration at 100 times magnification (10x) (Figure 4G) at higher magnification (400 times (40x)) the pregnant mother kidney showed increase of urinary space (Figure $4 \mathrm{H}$ ). The group 5 treated pregnant mother kidney showed moderate interstitial hemorrhages, necrosis of renal corpuscles, congestion and degeneration of proximal and distal convoluted tubules, degeneration of medullary rays and collecting ducts at 100 times magnification (10x) (Figure 4I) at higher magnification (400 times (40x)) the pregnant mother kidney also showed increased urinary space, proximal and distal convoluted tubules degeneration, atrophy of renal corpuscles which found to be higher in comparison to group 4 (Figure 4J). The group 6 treated pregnant mother kidney showed multiple interstitial hemorrhagic patches, maximum number and severe Malpighian corpuscular atrophy, severe degeneration of proximal and distal convoluted tubules at 100 times magnification (10x) (Figure $4 \mathrm{~K}$ ) at higher magnification (400 times (40x)) the pregnant mother kidney also showed increased urinary space, severe degenerations of lining cells of proximal and distal convoluted tubules which is found higher in comparison to group 5 (Figure 4L). The group 7 treated pregnant mother kidney showed highest percentage of renal corpuscular atrophy, absence of renal corpuscles, severe degenerations of proximal and distal convoluted tubules and their lining cells either absence of alignment disturbance at 100 times magnification (10x) (Figure 4M) at higher magnification (400 times (40x)) the pregnant mother kidney also showed highest intensity of increase of urinary space, severe congestion of proximal and distal convoluted tubules which is found higher intensity in comparison to group 6 (Figure $4 \mathrm{~N}$ ), whereas in histological deviations of treated fetuses group 2, 3, 4, 5, 6 and 7 treated fetuses kidney showed certain degenerative changes as compared to the control group 1 (Figure 5A). At higher doses the fetal treated kidney showed marked degenerative changes. The group 2 treated fetuses' kidney showed no changes when compared to that of the normal control (group A) (Figure 5B) at higher magnification (400 times (40x)) group 2 also showed almost no changes. The group 3 treated fetuses' kidney showed the same, same feature as that of the normal control group 1 (Figure 5C).The group 4 treated fetus kidney showed moderate congestion of inner lumen of proximal convoluted tubule and distal convoluted tubule, moderate degeneration with break of the wall of proximal and distal convoluted tubule it's dysmorpholgy, degeneration of lining Podocytic and Glomerular with other cells of proximal convoluted tubules at 400 times magnification (40x) the group 4 treated mother kidney also showed mild to moderate damage (Figure 5D). The group 5 treated fetus kidney showed multiple discrete hemorrhagic patches, severe congestion of inner lumen of proximal and distal convoluted tubules, break in the wall of proximal convoluted tubules, degeneration, severe atrophy or even absence of renal corpuscles and increase of urinary space, lymphocyte infiltration at 400 times magnification (40x) the group 5 treated mother kidney also showed mild to moderate damage (Figure 5E) same thing is observed in 6 and 7 treated group fetuses but the intensity of such feature increased in comparison to 4 and 5 treated group (Figure 5F and 4G) Small size silver nano particles which initiates toxicity, corrosion and damage in mature and developing kidney tissues, shows an specific dose-dependent nature, that is, in the higher dose oral ingestion small size silver nano particles demonstrated severe corrosive and hazardous gross and histological threats to the kidney tissues of the experimental mice and fetuses. Various ways through which silver nano particles entered into the body; such as respiratory, oral and intravenous, their nephrotoxic dilemmas due to their extreme tiny size have been framed and different dose inter relation evaluated $[46,47]$. In this existing experiment conducted with 6 different doses (lower, in between and higher dose) of colloidal silver nano particles serial ( 5 to 15 gestational age) orally induce on mice and fetuses, it was observed that after dissection and tissue investigation of the control and lower dose $(0.35,0.55 \mathrm{mg} / \mathrm{kg}$ b.w.) orally receiving groups with 2.75 to $18.5 \mathrm{~nm}$ size ranges, there was no difference or very slight difference in the mature and developing kidney tissues when compared with control. While in two higher doses (12 and $16 \mathrm{mg} / \mathrm{kg}$ b.w.), there was significant difference in the mature and developing kidney tissues when compared with control while 4 and $8 \mathrm{mg} / \mathrm{kg}$ b.w. group showed in between results [48]. In a particular past study, it was evidenced that when mice were experimented by 28 days serially oral bolus ingestion of 29,290 and $9,90 \mathrm{mg} / \mathrm{kg}$ dose of small size colloid silver nano particles $(50 \mathrm{~nm})$ in carboxyl methyl cellulose, the same did not initiate any significant changes in body weight. Silver nanoparticle are liberated out from the mature and developing kidney through urine by macrophages due to phagocytosis process, repeated application of this procedure hold responsible for regeneration of higher oxygen radicals. The generation of singlet oxygen in adequate manner was initiated by lyses cell membrane and organ dysfunction. In this existing study, we reported Glomerular necrosis and proximal convoluted tubule (PCT) damage and congestion of both mature and developing kidney in higher dose. Glomerular ailments are due to immunological disturbances, but tubules damage and congestion are mostly due to induction of toxins. On the contrary, anatomy of these vital organs land up to damage and disruption histologically and gross anatomically [11]. In this experiment, the proximal convoluted tubule (PCT) and 
Citation: Prakash PJ, Royana S, Sankarsan P (2017) Small Size Silver Nanoparticle's Corrosive and Hazardous Manifestations on Mature and Developing Kidney Following Accumulation in Pregnant Mice and Offspring's after Serial Oral Bolus Experimental Application: A New Chapter in Teratogenicity and Toxicity Search. J Cytol Histol 8: 467. doi: 10.4172/2157-7099.1000467

distal convoluted tubule (DCT) congestion and dysmorphology caused by the toxic effects of small size silver nano particles increased water pressure in Glomerulus in acute manner and arouses Glomerular hypertrophy. Some nanotoxicology scientists propounded that small size colloidal silver nanoparticles arouses mature and developing kidney toxicity, at high dose land up to fatal stage [49]. In this existing and present research, small size colloidal silver nanoparticles also arouses histological and gross changes in mature and developing kidneys; So, various categories of small size colloidal silver nanoparticles can be toxic in human and animal kidney tissues at different doses [50]. We hope with more researches (in relation with nephrotoxicity in small size silver nanoparticles and various lower and higher doses) structural and dimensional effects of same silver nano utilization and relevance on mature and developing kidney tissues may be cleared and clarified.

\section{Conclusion}

The aim and objective of this existing study was to evaluate the potential and adversified nephrotoxicity risk correspond to lower and higher dose of 2.75 to $18.5 \mathrm{~nm}$ size range colloidal silver nano. The corrosive and hazardous effects of nanosilver on mature and developing kidney tissues which were investigated are insignificant at lower and in between dose (2, 3, 4, 5 groups) but significant at higher dose ( 6 and 7 groups) in comparison to group 1(double distilled water control) of colloidal silver nano (AgNps) treatment in morphological and histological aspect and comparative experiments showed the histological damages in the kidney tissues directly proportional to dose where intensity of increase of such damages corresponds to experimental increase of dose of colloid nanosilver. The hazardous histological signs increase from mild ( 2 and 3 group) to mild to moderate (4 and 5 group) and finally moderate to severe (6 and 7 group) sequence. So final conclusion indicates, increase morphological and histological damage in mature and developing kidney depends directly on increase colloid silvernano dose. The deteriorative effects in all kidney cells caused because of sharp and spiny with thorny surfaces with projections present in small size silver nanoparticles, the persistent deposition of such in kidney will allow damage of other morphological structures along with histological structures which includes all kidney cells and all histomorphological parts of mature and developing kidney.

Overall conclusion of present study indicates small size nanosilver cause severe damages to mature and developing kidney because of nephrotoxic effect. The damages are seen in histological as well as morphological view. The intensity of such kidney damages corresponds to size and dose of nanosilver in form of colloidal solution when injected through oral route for experiment.

\section{Conflict of Interest}

The authors declare no conflict of research interest.

\section{Funding Sources}

This work was financially supported by the Grants of UGC and minor division, 5012 scheme of IMS, BHU which is promoted from Hon'ble Parliament of India.

\section{Acknowledgements}

This work was supported by the Department of Anatomy Institute of Medical Sciences Banaras Hindu University, Varanasi, Uttarpradesh, India, 221005.

\section{References}

1. Theivasanthi T, Alagar M (2011) Antibacterial Studies of Silver Nanoparticles. arXiv preprint arXiv: 11010348

2. Linkov I, Satterstrom FK, Corey LM (2008) Nanotoxicology and nanomedicine: making hard decisions. Nanomedicine: Nanotechnol Biol Med 4: 167-171.
3. Seaton A, Donaldson K (2005) Nanoscience, nanotoxicology, and the need to think small. Lancet 365: 923-924.

4. Lara HH, Garza-Treviño EN, IxtepanTurrent $L$ (2011) Silver nanoparticles are broad-spectrum bactericidal and virucidal compounds. J Nanobiotechnology 9 : 30.

5. Pronk M, Wijnhoven SW, Bleeker E (2009) Nanomaterials under REACH Nanosilver as a case study. RIVM rapport 601780003.

6. Knetsch ML, Koole LH (2011) New strategies in the development of antimicrobial coatings: the example of increasing usage of silver and silver nanoparticles. Polymers 3: 340-366.

7. Song X-I, Li B, Xu K (2012) Cytotoxicity of watersoluble mPEG-SH-coated silver nanoparticles in HL-7702 cells. Cell Biol Toxicol 28: 225-237.

8. Tiwari DK, Jin T, Behari J (2011) Dose-dependent in-vivo toxicity assessment of silver nanoparticle in Wistar rats. Toxicol Mech Methods 21: 13-24.

9. Atiyeh BS, Costagliola M, Hayek SN (2007) Effect of silver on burn wound infection control and healing: review of the literature. Burns 33: 139-148.

10. Sardari RR, Zarchi SR, Talebi A (2012) Toxicological effects of silver nanoparticles in rats. Afr J Microbiol Res 6: 5587-5593.

11. Park E, Bae E (2010) Repeated-dose toxicity and inflammatory responses in mice by oral administration of silver nanoparticles. Environ Toxicol Pharm 30 : 162-168.

12. Kim JS, Song KS, Sung TH (2013) Genotoxicity, acute oral and dermal eye and dermal irritation and corrosion and skin sensitization evaluation of silver nanoparticles. Nantoxicology 7: 953-960.

13. Braydich-Stolle L, Hussain S, Schlager JJ (2005) In vitro cytotoxicity of nanoparticles in mammalian germline stem cells. Toxicol Sci 88: 412-419.

14. Tang J (2008) Status of biological evaluation on silver nanoparticles. J Biomed Eng 25: 958-961.

15. Fan FRF, Bard AJ (1999) Imaging of biological macro molecules on mica in humid air. Proc Natl Acad Sci USA 96: 14222-14227.

16. Walker M, Parsons D (2012) The biological fate of silver ions following the use of silver-containing wound care products - a review. Int Wound J 11: 496-504.

17. Kim YS, Kim JS, Cho HS (2008) Twenty-eight-day oral toxicity, genotoxicity, and gender-related tissue distribution of silver nanoparticles in SpragueDawley rats. Inhal Toxicol 20: 575-583.

18. Kermanizadeh A, Gosens I, MacCalman L (2016) "A Multi laboratory Toxicological Assessment of a Panel of 10 Engineered Nanomaterials to Human Health - ENPRA Project - The Highlights, Limitations and Current and Future Challenges." Journal of Toxicology and Environmental Health B 19 1-28.

19. Jyoti K, Baunthiyal M, Singh A (2016) Characterization of silver nanoparticles synthesized using Urtica dioica Linn. leaves and their synergistic effects with antibiotics. Journal of Radiation Research and Applied Sciences 3: 217-227.

20. Ibrahim HM (2015) Green synthesis and characterization of silver nanoparticles using banana peel extract and their antimicrobial activity against representative microorganisms," Journal of Radiation Research and Applied Sciences 8: 3 265-275,

21. Ahmed S, Saifullah, Ahmad M (2016) Green synthesis of silver nanoparticles using Azadirachta indica aqueous leaf extract. Journal of Radiation Research and Applied Sciences 9: 1-7.

22. EPA (2015)Takes action to protect public from an illegal nano silver pesticide in food containers cites NJ Company for selling food containers with an unregistered pesticide warns large retailers not to sell these products.

23. EPA (2015) Announces Registration of nanosilver pesticide product.

24. Gaillet S, Rouanet JM (2015) Silver nanoparticles: their potential toxic effects after oral exposure and underlying mechanisms-a review. Food Chem Toxicol 77: $58-63$

25. Bekele AZ, Gokulan K, Williams KM (2016) Size-dependent antiviral effects of silver nanoparticles on feline calicivirus, a human norovirus surrogate. Foodborne Pathogens Dis 13: 239-244.

26. Verleysen E, Van Doren E, Waegeneers N (2015) TEM and SP-ICP-MS analysis of the release of silver nanoparticles from decoration of pastry. J Agric Food Chem 63: 3570-3578. 
Citation: Prakash PJ, Royana S, Sankarsan P (2017) Small Size Silver Nanoparticle's Corrosive and Hazardous Manifestations on Mature and Developing Kidney Following Accumulation in Pregnant Mice and Offspring's after Serial Oral Bolus Experimental Application: A New Chapter in Teratogenicity and Toxicity Search. J Cytol Histol 8: 467. doi: 10.4172/2157-7099.1000467

Page 10 of 10

27. Williams K, Milner J, Boudreau MD (2015) Effects of subchronic exposure of silver nanoparticles on intestinal microbiota and gut-associated immune responses in the ileum of SpragueDawley rats. Nanotoxicology 9: 279-289.

28. Bastos V, de Oliveira JF, Brown D (2016) The influence of Citrate or PEG coating on silver nanoparticle toxicity to a human keratinocyte cell line. Toxicol Lett 249: 29-41.

29. Boudreau MD, Imam MS, Paredes AM (2016) Differential effects of silver nanoparticles and silver ions on tissue accumulation, distribution, and toxicity in the Sprague Dawley rat following daily oral gavage administration for 13-Weeks. Toxicol Sci 150: 131-160.

30. Georgantzopoulou A, Serchi T, Cambier S (2016) Effects of silver nanoparticles and ions on a co-culture model for the gastrointestinal epithelium. Part Fibre Toxicol 13: 9.

31. Gordon S, Daneshian M, Bouwstra J (2015) Non-animal models of epithelial barriers (skin, intestine and lung) in research, industrial applications and regulatory toxicology. Altern Animal Exp ALTEX 32: 327-378.

32. Solomon SD, Bahadory M Jeyarajasingam AV (2007) Synthesis and study of silver nanoparticles. J Chem Educ 84: 322-325.

33. Auffan MV, Rose J, Wiesner MR (2009) Chemical stability of metallic nanoparticles: a parameter controlling their potential cellular toxicity in vitro. Environ Pollut 157: 1127-1133.

34. Powers CM, Badireddy AR, Ryde IT (2011) Silver nanoparticles compromise neurodevelopment in PC12 cells: Critical contributions of silver ion, particle size, coating and composition. Environ Health Perspect 119: 37-44.

35. Sahu SC, Zheng J, Graham L (2014) Comparative cytotoxicity of nanosilver in human liver HepG2 and collon Caco2 cells in culture. J Appl Toxicol 34: 1155-1166.

36. Farkas J, Christian P, Gallego-Urrea JA (2011) Uptake and effects of manufactured $X$ nanoparticles in rainbow trout (Oncorhynchus mykiss) gill cells RID F-3693-2010. Aquat Toxicol 101: 117-125

37. Liu W, Wu Y, Wang C (2010) Impact of silver nanoparticles on human cells: effect of particle size. Nanotoxicology 4: 319-330.

38. Behra R, Sigg L, Clift MJD (2013) Bioavailability of silver nanoparticles and ions: from a chemical and biochemical perspective. J R Soc Interface 10 20130396.

39. McShan D, Ray PC, Yu H (2014) Molecular toxicity mechanism of nanosilver. J Food Drug Anal 22: 116-127.

40. Walker M, Parsons D (2012) The biological fate of silver ions following the use of silver-containing wound care products - a review. Int. Wound J.

41. Dziendzikowska K, Gromadzka-Ostowska J, Lankoff A (2012) Time-dependent biodistribution and excretion of silver nanoparticles in male Wistar rats. J Appl Toxicol 32: 920-928.

42. Wang Z, Li N, Zhao J (2012) CuO nanoparticle interaction with human epithelial cells: cellular uptake, location, export, and genotoxicity. Chem Res Toxicol 25 1512-1521.

43. AshaRani PV, Kah Mun GL, Prakash Hande M, Valiyaveettil S (2009) Cytotoxicity and genotoxicity of silver nanoparticles in human cells. ACS Nano 3: $279-290$.

44. Lok CN, Ho CM, Chen R (2007) Silver nanoparticles: Partial oxidation and antibacterial activities. J Biol Inorg Chem 12: 527-534.

45. Liu JY, Hurt RH ( 2010) Ion release kinetics and particle persistence in aqueous nano-silver colloids. Environ Sci Technol 44: 2169-2175.

46. Edwards-Jones $V(2009)$ The benefits of silver in hygiene, personalcare and healthcare. Lett Appl Microbiol 49: 147-152.

47. Nel A, Xia T, Mädler L (2006) Toxic potential of materials at the nanolevel. Science 311: 622-627.

48. Hendi A (2010) Silver nanoparticles mediate diffrential responses in some of liver and kidney functions during skin woud healing. J King Saud Univ Sci 18 71-76.

49. Miura N, Shinohara $Y$ (2009) Cytotoxic effect and apoptosis induction by silver nanoparticles in hela cells. Biochem Biophys Res Commun 390(3): 733-737.

50. Choi JE, Kim S, Ahn JH (2009) Induction of oxidative stress and apoptosis by silver nanoparticles in the liver of adult zebrafish. Aquat Toxicol Epub Ahead of print (PMID): 20060176. 